\title{
INFRACCIONES A LOS DERECHOS DE AUTOR EN MÉXICO CON RELACIÓN AL ENTORNO DIGITAL.
}

\section{INFRINGEMENTS OF COPYRIGHT IN MEXICO IN RELATION TO THE DIGITAL ENVIRONMENT.}

\section{Fernando SOLER AGUILAR. ${ }^{1}$}

Resumen. Con el presente trabajo presentamos al lector una visión panorámica del sistema de protección de los Derechos de Autor en México con relación al entorno digital, para ello iniciamos con una breve revisión a los conceptos fundamentales del Derecho Intelectual, los Derechos de Autor, los Derechos Morales, los Derechos Patrimoniales, su naturaleza jurídica, su regulación en la Ley Federal del Derecho de Autor, el concepto de infracción, clases de infracciones, la legislación aplicable, las autoridades competentes, las infracciones en materia de derecho de autor y sus sanciones, las infracciones en materia de comercio y sus sanciones, la reparación del daño administrativa, el procedimiento administrativo, los delitos en materia de derechos de autor, la reparación del daño penal, tesis jurisprudencial relevante y una serie de conclusiones.

Abstract. With this work we present the reader with a panoramic view of the copyright protection system in Mexico in relation to the digital environment. We begin with a brief review of the fundamental concepts of Intellectual Law, Copyright, Moral Rights, the Patrimonial Rights, its juridical nature, and then, we focus on its regulation in the Federal Copyright Law, the concept of infringement, classes of infractions, the applicable legislation, the competent authorities, the infractions in the matter of copyright and its

\footnotetext{
${ }^{1}$ El autor es Licenciado en Derecho con Especialidad en Derecho de la Propiedad Intelectual por la Universidad Nacional Autónoma de México. Actualmente, se desempeña como Abogado Senior en el Despacho Lex Informática en la Ciudad de México y como Tutor a Distancia de la Academia de la Organización Mundial de la Propiedad Intelectual (OMPI). Contacto Personal: fernandosoleraguilar@gmail.com
} 
sanctions, the infringements in matters of commerce and their sanctions, the repair of administrative damage, the administrative procedure, the crimes in the matter of copyright, the reparation of the criminal damage, relevant jurisprudential thesis and a series of conclusions.

Palabras clave: Propiedad intelectual, Derechos de Autor, Infracciones de Derechos de Autor.

Keywords: Intellectual Property, Copyright, Infringement of Copyright.

\section{Notas introductorias}

El presente documento surge con motivo de la invitación de la maestra Evelyn Téllez Carvajal a participar en el Segundo Coloquio de Primavera en Propiedad Intelectual: "Software Libre, Repositorios y Derechos de Autor", organizado por INFOTEC, Centro Público de Investigación e Innovación en Tecnologías de la Información y Comunicación del CONACYT, LEX INFORMÁTICA, CENTRO WAH, el Centro de Investigación e Informática Jurídica de la Escuela Libre de Derecho y la Coordinación de Colecciones Universitarias Digitales de la Universidad Nacional Autónoma de México, mismo que se llevó a cabo en la Ciudad de México los días 30 y 31 de mayo de 2018.

Tal y como se indicó en la convocatoria correspondiente, dicho evento tuvo como objetivo debatir ideas y encontrar respuestas a las interrogantes que surgen derivado de los derechos de los autores y sus obras respecto a su difusión por medio de los denominados repositorios digitales. Ya que, por un lado, se tienen los derechos de los autores y por el otro, las obligaciones de ciertas instituciones públicas a dar acceso abierto a todas aquellas investigaciones que se encuentren en desarrollo o que se hayan desarrollado con el beneficio de financiamiento público. 
En este contexto, buscamos poner a disposición de los asistentes a dicho evento y en consecuencia, de los lectores del presente documento; los aspectos generales que integran el sistema de protección de los Derechos de Autor en México, lo anterior, con la intención de sentar las bases teórico-jurídicas que permitan abordar el tema con conocimiento de las reglas generales correspondientes así como de las autoridades competentes en la materia, con relación al entorno digital.

Se estima relevante lo anterior, en virtud de que con este ejercicio será posible identificar con mayor precisión las figuras de protección que resultan aplicables, el alcance de los derechos correspondientes, así como el camino a seguir en caso de que un autor tenga conocimiento de la explotación no autorizada de su obra por un tercero, o en su caso, un tercero tenga la posibilidad de identificar si incurre en alguno de los supuestos de infracción contenidos en las leyes aplicables, la autoridad competente en cada caso, así como las sanciones a las que podría hacerse acreedor, con lo cual estará en aptitud de determinar el riesgo de hacerse acreedor a algún tipo de sanción por explotación no autorizada de una obra.

Así pues, abordaremos este tema partiendo de lo general a lo particular, y para ello, identificamos conceptos básicos y procedemos a su definición:

\section{Derecho Intelectual}

En primer término, consideramos oportuno hacer referencia a la rama del Derecho que se encarga del estudio de las normas que regulan y protegen el producto del intelecto humano, a saber, el Derecho Intelectual, al respecto, el Doctor David Rangel Medina define al Derecho intelectual como: el conjunto de normas que regulan las prerrogativas y beneficios 
que las leyes reconocen y establecen en favor de los autores y de sus causahabientes por la creación de obras artísticas, científicas, industriales y comerciales. ${ }^{2}$

A su vez, el mismo autor identifica las dos partes que lo integran y hace una breve referencia a su objeto de protección:

Por un lado, señala a los Derechos de Autor, cuyo objeto de protección consiste en las obras que apuntan a la satisfacción de sentimientos estéticos o tienen que ver un campo del conocimiento y de la cultura en general, misma que adquiere particular relevancia en el entorno digital, en virtud de que el tráfico en Internet precisamente consiste en intercambio de información que es desarrollada por un autor, titular de una serie de derechos susceptibles de protección.

Por otro lado, menciona a la Propiedad Industrial que se ocupa de la protección de la actividad del intelecto humano cuando se aplica a la búsqueda de soluciones concretas de problemas específicos en el campo de la industria. ${ }^{3}$ De igual modo, resulta relevante en el entorno digital, ya que se puede encontrar presente en el contenido que se intercambia bien sea a través de una marca registrada o hasta en la tecnología que permite llevar a cabo la acción descrita, por ejemplo: a través del programa de cómputo desarrollado para el almacenaje o distribución de contenido en la red mundial.

En el caso específico, hemos determinado ocuparnos de las infracciones de los Derechos de Autor en México con relación al entorno digital, un tema que no obstante resulta de actualidad consideramos que no ha sido suficientemente explorado por los agentes relacionados, a saber: los titulares de los derechos correspondientes, los abogados litigantes, las autoridades administrativas y penales competentes, así como los Tribunales que

\footnotetext{
${ }^{2}$ RANGEL MEDINA, D., Derecho Intelectual, UNAM-McGRAW HILL, México, 1998, p. 1.

${ }^{3}$ Idem.
} 
resuelven en última instancia las controversias relacionadas. Al efecto, partamos del análisis de la rama y el objeto de estudio correspondientes.

\section{Derechos de Autor}

La Doctora Delia Lipszyc, nos indica que el Derecho de Autor, es la rama del Derecho que regula los derechos subjetivos del autor sobre las creaciones que presentan individualidad, resultantes de su actividad intelectual, que habitualmente son enunciadas como obras literarias, musicales, teatrales, artísticas, científicas y audiovisuales. ${ }^{4}$

A su vez, la legislación mexicana, indica que los derechos de autor a los que se refiere, se reconocen respecto de las obras en las siguientes ramas: literaria; musical con o sin letra; dramática; danza; pictórica o de dibujo; escultórica y de carácter plástico; caricatura e historieta; arquitectónica; cinematográfica y demás obras audiovisuales; programas de radio y televisión; programas de cómputo; fotográfica; obras de arte aplicado que incluyen el diseño gráfico o textil, y de compilación, integradas por las colecciones de obras, tales como las enciclopedias, las antologías; y de obras u otros elementos como las bases de datos, siempre que dichas colecciones, por su selección o la disposición de su contenido o materias, constituyan una creación intelectual. Así como las demás obras que por analogía puedan considerarse obras literarias o artísticas que se incluirán en la rama que les sea más afín a su naturaleza. ${ }^{5}$

Ahora bien, los Derechos de Autor, se dividen en dos categorías plenamente identificadas: a saber, los derechos morales y los derechos patrimoniales, por lo que haremos referencia a su definición doctrinaria, legal y a las facultades que los integran, mismas que básicamente

\footnotetext{
${ }^{4}$ LIPSZYC, D. Derecho de Autor y Derechos Conexos, UNESCO/CERLALC/ZAVALIA, Argentina, 1993, p. 11.

${ }^{5}$ Artículo 13 de la LFDA.
} 
constituyen las bases sobre las cuales se construyen los supuestos de infracción correspondientes.

\section{Derechos morales}

La autora citada previamente, los identifica como facultades de carácter personal concernientes a la tutela de la personalidad del autor en relación con su obra, destinadas a garantizar intereses intelectuales. ${ }^{6}$

Con relación a este tipo de derechos, la legislación mexicana no establece como tal una definición, sino que hace referencia a una serie de atributos o reglas que los rigen: el autor es el único, primigenio y perpetuo titular de los derechos morales sobre las obras de su creación; el derecho moral se considera unido al autor y es inalienable, imprescriptible, irrenunciable e inembargable y corresponde el ejercicio del derecho moral, al propio creador de la obra y a sus herederos. En ausencia de éstos, o bien en caso de obras de dominio público, anónimas o de las protegidas por el Título VII de la Ley, el Estado los ejercerá siempre y cuando se trata de obras de interés para el patrimonio cultural nacional. ${ }^{7}$

El Doctor Eduardo de la Parra, enlista las siguientes facultades:
a) Facultad de divulgación.
b) Facultad de paternidad.
c) Facultad de integridad.
d) Facultad de retracto, arrepentimiento o retirada del comercio o circulación. ${ }^{8}$

\footnotetext{
${ }^{6}$ LIPSZYC, D., ob cit. p. 11.

${ }^{7}$ Artículos 18, 19 y 20 LFDA.

${ }^{8}$ DE LA PARRA, E., Derechos Humanos y Derechos de Autor, Universidad Nacional Autónoma de México e Instituto de Investigaciones Jurídicas, México, 2010, pp. 212-226.
} 
La Ley mexicana indica que los titulares de los derechos morales podrán en todo tiempo:

I. Determinar si su obra ha de ser divulgada y en qué forma, o la de mantenerla inédita;

II. Exigir el reconocimiento de su calidad de autor respecto de la obra por él creada y la de disponer que su divulgación se efectúe como obra anónima o seudónima;

III. Exigir respeto a la obra, oponiéndose a cualquier deformación, mutilación u otra modificación de ella, así como a toda acción o atentado a la misma que cause demérito de ella o perjuicio a la reputación de su autor;

IV. Modificar su obra;

V. Retirar su obra del comercio, y

VI. Oponerse a que se le atribuya al autor una obra que no es de su creación. ${ }^{9}$

\section{Derechos patrimoniales}

Sobre este particular, la Doctora Delia Lipszyc, indica que el derecho patrimonial del autor consiste en el derecho a la explotación económica de la obra, que el autor puede realizar por sí o autorizando a otros. ${ }^{10}$

El ordenamiento legal aplicable, establece textualmente lo siguiente:

"En virtud del derecho patrimonial, corresponde al autor el derecho de explotar de manera exclusiva sus obras, o de autorizar a otros su explotación, en cualquier forma,

\footnotetext{
${ }^{9}$ Artículo 21 LFDA.

${ }^{10}$ Ob. Cit., p. 12.
} 
dentro de los límites que establece la presente Ley y sin menoscabo de la titularidad de los derechos morales a que se refiere el artículo 21 de la misma." 11

Además, se fijan una serie de especificaciones en los siguientes términos: es titular del derecho patrimonial el autor, heredero o el adquirente por cualquier título; el autor es el titular originario del derecho patrimonial y sus herederos o causahabientes por cualquier título, serán considerados titulares derivados; el autor y su causahabiente gozarán del derecho de percibir una regalía por la comunicación o transmisión pública de su obra por cualquier medio. ${ }^{12}$

Por otra parte, el Doctor Eduardo de la Parra, ${ }^{13}$ refiere de forma específica que el ámbito patrimonial del autor, se integra de los siguientes derechos:
a) Derecho de reproducción.
b) Derecho de distribución.
c) Derecho de comunicación pública.
d) Derecho de transformación.

Dichas prerrogativas se reflejan en el conjunto normativo, al señalar que los titulares de los derechos patrimoniales podrán autorizar o prohibir:

I. La reproducción, publicación, edición o fijación material de una obra en copias o ejemplares, efectuada por cualquier medio ya sea impreso, fonográfico, gráfico, plástico, audiovisual, electrónico, fotográfico u otro similar.

II. La comunicación pública de su obra a través de cualquiera de las siguientes maneras:

\footnotetext{
${ }^{11}$ Artículo 24 LFDA.

${ }^{12}$ Artículos 25, 26 y 26 bis LFDA.

${ }^{13}$ Ob. Cit., pp. 227-249.
} 
a) La representación, recitación y ejecución pública en el caso de las obras literarias y artísticas;

b) La exhibición pública por cualquier medio o procedimiento, en el caso de obras literarias y artísticas, y

c) El acceso público por medio de la telecomunicación;

III. La transmisión pública o radiodifusión de sus obras, en cualquier modalidad, incluyendo la transmisión o retransmisión de las obras por:
a) Cable;
b) Fibra óptica;
c) Microondas;
d) Vía satélite, o
e) Cualquier otro medio conocido o por conocerse.

IV. La distribución de la obra, incluyendo la venta u otras formas de transmisión de la propiedad de los soportes materiales que la contengan, así como cualquier forma de transmisión de uso o explotación. Cuando la distribución se lleve a cabo mediante venta, este derecho de oposición se entenderá agotado efectuada la primera venta, salvo en el caso expresamente contemplado en el artículo 104 de la Ley;

V. La importación al territorio nacional de copias de la obra hechas sin su autorización;

VI. La divulgación de obras derivadas, en cualquiera de sus modalidades, tales como la traducción, adaptación, paráfrasis, arreglos y transformaciones, y

VII. Cualquier utilización pública de la obra salvo en los casos expresamente establecidos en la Ley. ${ }^{14}$

Al respecto, de igual modo el cuerpo normativo de referencia, indica que dichas facultades son independientes entre sí y cada una de las modalidades de exploración también lo son y

\footnotetext{
${ }^{14}$ Artículo 27 LFDA.
} 
que los derechos patrimoniales estarán vigentes durante la vida del autor y, a partir de su muerte, cien años más. Cuando la obra pertenezca a varios coautores los cien años se contarán a partir de la muerte del último, y cien años después de divulgadas.

Si el titular del derecho patrimonial distinto del autor muere sin herederos la facultad de explotar o autorizar la explotación de la obra corresponderá al autor y, a falta de éste, corresponderá al Estado por conducto del Instituto, quien respetará los derechos adquiridos por terceros con anterioridad. Pasados los términos previstos, la obra pasará al dominio público. $^{15}$

\section{Naturaleza Jurídica}

Una vez establecido con precisión el conjunto de prerrogativas morales y patrimoniales con las que cuenta un autor o su causahabiente de conformidad con la Ley de la materia resulta oportuno indicar que es precisamente sobre dicha base legal que el titular podrá iniciar acciones legales en contra de un tercero por la violación de cualquiera de sus derechos patrimoniales, de forma independiente y en cualquiera de sus modalidades.

Sobre el particular, consideramos oportuno subrayar que la naturaleza jurídica de los Derechos de Autor es la de un Ius Prohibendi, como lo indica el Doctor Eduardo de la Parra, ya que por virtud de la Ley existe una prohibición de usar la obra por todo aquél que no sea su autor. ${ }^{16}$ A mayor abundamiento, el autor citado subraya que: "los derechos de explotación son derechos exclusivos o de exclusiva, es decir, permiten a su titular gozar de un bien (en este caso inmaterial: la obra), con exclusión de cualquier tercero. De ahí que se

\footnotetext{
15 Artículos 28 y 29 LFDA.

${ }^{16}$ Ob. Cit., p. 229-231.
} 
les suela llamar monopolios legales, pues, en principio, excluyen a otros de la explotación de la obra". ${ }^{17}$

Lo anterior, trae aparejado como consecuencia que los derechos de explotación sean oponibles erga omnes. Esta regla general, quedó plasmada por el legislador en los artículos 11 y 24 de la LFDA. Toda vez que previamente analizamos el contenido del artículo 24, en este apartado procedemos a la transcripción del artículo 11 para mejor comprensión:

"El derecho de autor es el reconocimiento que hace el Estado en favor de todo creador de obras literarias y artísticas previstas en el artículo 13 de esta Ley, en virtud del cual otorga su protección para que el autor goce de prerrogativas y privilegios exclusivos de carácter personal y patrimonial. Los primeros integran el llamado derecho moral y los segundos, el patrimonial."

Por lo tanto, y debido a la naturaleza del Derecho de Autor que se ha descrito, es posible que su infracción se actualice a cada momento y que su titular ni siquiera se haya enterado, por lo que no será sino hasta que tenga conocimiento y oponga su derecho frente a un tercero ante la autoridad competente; que el aparato del Estado actuará en consecuencia.

\section{Infracción}

Para entrar en materia, consideramos oportuno remitirnos a la definición de infracción que nos propone el Doctor David Rangel Medina, quien al efecto señala que se entiende por infracción: "Toda utilización no autorizada de una obra protegida por derecho de autor, cuando dicha autorización es necesaria conforme a la Ley." 18

\footnotetext{
${ }^{17}$ Idem., p. 229.

${ }^{18}$ Ob. Cit., p. 183.
} 
En términos de lo establecido a lo largo del presente, por utilización entendemos el ejercicio no autorizado o la violación de algún Derecho de Autor, en cualquiera de sus dos vertientes: derechos morales o derechos patrimoniales. Por lo tanto, en ese supuesto, el autor y/o el causahabiente, se encuentran legitimados para iniciar las acciones legales correspondientes, para ello deberán en primer lugar, identificar con precisión la conducta infractora a fin de saber cuál es el ordenamiento legal aplicable, así como la autoridad competente para conocer del asunto.

Al efecto, el autor referido en este apartado nos propone la siguiente clasificación de las infracciones en tres grupos:

Primer grupo: infracciones en materia de derechos de autor. ${ }^{19}$

Segundo grupo: infracciones en materia de comercio. ${ }^{20}$

Tercer grupo: delitos en materia de derechos de autor. ${ }^{21}$

De lo que antecede, podemos advertir a grandes rasgos que el primer grupo se refiere a los derechos morales, el segundo grupo a los derechos patrimoniales y el tercer grupo a los derechos patrimoniales. No obstante, tal y como lo indicamos previamente, para ejercer las acciones legales que correspondan; lo procedente será identificar el ordenamiento legal aplicable para cada caso en particular.

\section{Legislación}

Con relación a este tema en específico, podemos partir de la premisa general de que la legislación aplicable en materia de infracciones de Derechos de Autor en México es la siguiente:

\footnotetext{
${ }^{19}$ Artículos 229 y 230 LFDA.

${ }^{20}$ Artículos 231 al 236 LFDA.

${ }^{21}$ Artículos 424 al 429 del Código Penal Federal.
} 
a) Ley Federal del Derecho de Autor. Nueva Ley publicada en el Diario Oficial de la Federación el 24 de diciembre de 1996. Última reforma publicada en el DOF el 13 de enero de 2016.

b) Reglamento de la Ley Federal del Derecho de Autor. Nuevo Reglamento publicado en el Diario Oficial de la Federación el 22 de mayo de 1988. Última reforma publicada DOF el 14 de septiembre de 2005.

c) Ley de la Propiedad Industrial. Publicada en el Diario Oficial de la Federación el 27 de junio de 1991. Última reforma publicada en el DOF el 18 de mayo de 2018.

d) Reglamento de la Ley de la Propiedad Industrial. Nuevo Reglamento publicado en el Diario Oficial de la Federación el 23 de noviembre de 1994. Última reforma publicada en el DOF el 16 de diciembre de 2016.

e) Ley Federal de Procedimiento Administrativo. Nueva Ley publicada en el Diario Oficial de la Federación el 4 de agosto de 1994. Última reforma publicada en el DOF el 18 de mayo de 2018.

f) Código Federal de Procedimientos Civiles. Nuevo Código publicado en el Diario Oficial de la Federación e 24 de febrero de 1943. Última reforma publicada en el DOF el 09 de abril de 2012.

g) Ley Aduanera. Nueva Ley publicada en el Diario Oficial de la Federación el 15 de diciembre de 1995. Última reforma publicada en el DOF el 01 de junio de 2018.

h) Código Penal Federal. Nuevo Código publicado en el Diario Oficial de la Federación el 14 de agosto de 1931. Últimas reformas publicadas en el DOF el 21 de junio de 2018.

i) Código Nacional de Procedimientos Penales. Nuevo Código publicado en el Diario Oficial de la Federación el 05 de marzo de 2014. Última reforma publicada en el DOF el 17 de junio de 2016. 
Del conjunto normativo que antecede, se advierten tanto las leyes sustantivas como adjetivas indispensables que el titular de los derechos de autor susceptibles de infracción debe tomar en cuenta para iniciar acciones legales en contra de un tercero en México. ${ }^{22}$

\section{Autoridades}

Del marco jurídico de referencia que se ha descrito previamente, es posible desprender los órganos competentes para conocer de controversias relacionadas con la violación de los Derechos de Autor en la República Mexicana, mismos que se relacionan a continuación:

a) Instituto Nacional del Derecho de Autor (INDAUTOR). Órgano desconcentrado encargado de proteger y fomentar los derechos de autor; promover la creatividad; controlar y administrar el registro público del derecho de autor; mantener actualizado el acervo cultural de la nación y promover la cooperación internacional y el intercambio con instituciones encargadas del registro y protección del derecho de autor y los derechos conexos. ${ }^{23}$

El INDAUTOR, tiene facultades para: I. Realizar investigaciones respecto de presuntas infracciones administrativas, llevar a cabo visitas de inspección y requerir informes y datos; II. Solicitar a las autoridades competentes la práctica de visitas de inspección; III. Ordenar y ejecutar los actos provisionales para prevenir o terminar con la violación al derecho de autor y derechos conexos; IV. Imponer sanciones administrativas que sean procedentes, y V. Las demás que le

\footnotetext{
${ }^{22}$ Para una referencia de mayor amplitud sobre el régimen jurídico en materia de Derechos de Autor en México, recomendamos consultar la base de datos de la Organización Mundial de la Propiedad Intelectual denominada: WIPO Lex en la siguiente liga: http://www.wipo.int/wipolex/es/. Así como la página oficial de la Cámara de Diputados de los Estados Unidos Mexicanos, que cuenta con un motor búsqueda por tema en el siguiente enlace: $\mathrm{http}: / / \mathrm{www}$.diputados.gob.mx/.

${ }^{23}$ Fuente: https://www.indautor.gob.mx/ficha-descriptiva.php, consultada el 05 de julio de 2018.
} 
correspondan en los términos de la Ley, sus reglamentos y demás disposiciones aplicables. $^{24}$

b) Instituto Mexicano de la Propiedad Industrial (IMPI). Organismo público descentralizado con personalidad jurídica, patrimonio propio y autoridad legal para administrar el sistema de propiedad industrial en México. ${ }^{25}$

El IMPI, tiene facultades para realizar las investigaciones de presuntas infracciones administrativas; ordenar y practicar visitas de inspección; requerir información y datos; ordenar y ejecutar las medidas provisionales para prevenir o hacer cesar la violación a los derechos de propiedad industrial; oír en su defensa a los presuntos infractores, e imponer las sanciones administrativas correspondientes en materia de propiedad industrial; Prestar los demás servicios y realizar las actividades necesarias para el debido cumplimiento de sus facultades conforme a la Ley y a las demás disposiciones legales aplicables.

c) Unidad Especializada en Investigación de Delitos contra los Derechos de Autor y la Propiedad Industrial (UEIDDAPI). Es la Unidad Especializada en atender y proteger los derechos de propiedad intelectual e industrial, mediante la integración de un frente común constituido por autoridades administrativas, preventivas e investigadoras de delitos en esta materia y las organizaciones, organismos y empresas que ejercen derechos de autor y propiedad industrial.

La UEIDDAPI es frente institucional para el control y supervisión de la aplicación de la normatividad administrativa en materia de derechos de autor y propiedad industrial, así como para la prevención, investigación y persecución de

\footnotetext{
${ }^{24}$ Artículos 208, 209 y 210 de la LFDA.

${ }^{25}$ Fuente: https://www.gob.mx/impi/que-hacemos, consultada el 05 de julio de 2018.
} 
infracciones y delitos en dichas materias, mediante una sistemática y coordinada realización de acciones especializadas que se orienten a erradicar la impunidad y reducir la incidencia delictiva en la materia, mediante la formulación de propuestas de reformas legislativas que faciliten las acciones institucionales, de campañas de concientización para la prevención de tales ilícitos, de acciones contundentes contra el suministro de materia prima para la reproducción ilícita de bienes protegidos por las leyes de la materia, así como contra la producción, transportación, almacenamiento y comercialización de productos reproducidos ilegalmente. $^{26}$

De lo anterior, se advierte claramente que el sistema de protección de los Derechos de Autor en México cuenta con órganos especializados encargados de conocer las controversias relacionadas con las infracciones contenidas en los dispositivos legales de referencia. Sin embargo, existe una particularidad, tal y como se desprende del listado general de la legislación aplicable en estos casos, así como de la referencia a las autoridades competentes, de los procedimientos administrativos seguidos en forma de juicio por infracción a los Derechos de Autor, no sólo se ocupa el INDAUTOR, sino también el IMPI. Es precisamente la legislación autoral que de forma expresa señala que las infracciones en materia de derechos de autor serán sancionadas por el INDAUTOR con arreglo a lo dispuesto por la Ley Federal de Procedimiento Administrativo y a su vez, las infracciones en materia de comercio previstas en el mismo ordenamiento autoral serán sancionadas por el IMPI. ${ }^{27}$

1. Medidas provisionales y suspensión de la libre circulación de mercancías de procedencia extranjera en frontera.

\footnotetext{
${ }^{26}$ Fuente: https://www.gob.mx/pgr/acciones-y-programas/unidad-especializada-en-investigacion-de-delitoscontra-los-derechos-de-autor-y-la-propiedad-industrial, consultada el 05 de julio de 2018.

${ }^{27}$ Artículos 230 y 232 LFDA.
} 
Con arreglo al procedimiento y formalidades previstas en los Títulos Sexto y Séptimo de la LPI, el IMPI podrá adoptar las medidas precautorias previstas en el conjunto normativo de referencia y para tal efecto, tendrá las facultades de realizar investigaciones; ordenar y practicar visitas de inspección, requerir información y datos e incluso está facultado para emitir una resolución de suspensión de la libre circulación de mercancías de procedencia extranjera en frontera, en términos de lo dispuesto por la Ley Aduanera. ${ }^{28}$

Particularmente, podemos advertir que en los procedimientos de declaración administrativa relativos a la violación de los derechos que protege la LPI, el IMPI podrá adoptar las siguientes medidas:

I.- Ordenar el retiro de la circulación o impedir ésta, respecto de las mercancías que infrinjan derechos de los tutelados por la Ley;

II.- Ordenar se retiren de la circulación:

a) Los objetos fabricados o usados ilegalmente;

b) Los objetos, empaques, envases, embalajes, papelería, material publicitario y similares que infrinjan alguno de los derechos tutelados por la Ley;

c) Los anuncios, letreros, rótulos, papelería y similares que infrinjan alguno de los derechos tutelados por la Ley; y

d) Los utensilios o instrumento destinados o utilizados en la fabricación, elaboración u obtención de cualquiera de los señalados en los incisos a), b) y c), anteriores;

III.- Prohibir, de inmediato, la comercialización o uso de los productos con los que se viole un derecho de los protegidos por la Ley;

IV.- Ordenar el aseguramiento de bienes, mismo que se practicará conforme a lo dispuesto en los artículos 211 a 212 BIS 2 de la Ley;

\footnotetext{
${ }^{28}$ Artículos 234 y 235 LFDA.
} 
V.- Ordenar al presunto infractor o a terceros la suspensión o el cese de los actos que constituyan una violación a las disposiciones de la Ley, y

VI.- Ordenar se suspenda la prestación del servicio o se clausure el establecimiento cuando las medidas que se prevén en las fracciones anteriores, no sean suficiente para prevenir o evitar la violación a los derechos protegidos por la Ley.

Si el producto o servicio se encuentra en el comercio, los comerciantes o prestadores tendrán la obligación de abstenerse de su enajenación o prestación a partir de la fecha en que se les notifique la resolución.

Igual obligación tendrán los productores, fabricantes, importadores y sus distribuidores, quienes serán responsables de recuperar de inmediato los productos que ya se encuentren en el comercio. ${ }^{29}$

Visto lo que antecede, se desprende que la Ley de la materia contempla un amplio catálogo de opciones para elegir la que se ajuste a la conducta desplegada por el presunto infractor de los derechos de autor que correspondan. Es decir, en la medida de lo posible; el autor o su causahabiente, deben tener conocimiento de los actos que lleva a cabo el presunto infractor en su perjuicio o de los objetos sobre los cuales recae dicho actuar ya que con ello, podrá solicitar a la autoridad administrativa el aseguramiento de la mercancía o los objetos respectivos, o en su caso, que le ordene al presunto infractor o a terceros el cese de los actos que constituyan una violación a la Ley.

En consecuencia, en su escrito inicial de solicitud de imposición de medidas provisionales, deberá identificar con precisión la fracción y el inciso que corresponda. Además de considerar lo que al efecto establece el artículo 177 del Reglamento de la Ley Federal del Derecho de Autor, mismo que para pronta referencia se transcribe a continuación:

\footnotetext{
${ }^{29}$ Artículo 199 BIS LPI.
} 
“Artículo 177.- La aplicación de las medidas adoptadas por el Instituto Mexicano de la Propiedad Industrial, sin perjuicio de lo dispuesto en los artículos 199 bis y 212 bis de la Ley de la Propiedad Industrial, podrá recaer en:

I. Ejemplares de las obras, moldes, clisés, placas, libros, publicaciones periódicas, fonogramas y videogramas y en general, los instrumentos y los objetos fabricados, producidos o distribuidos en contravención a lo dispuesto por la Ley o este Reglamento;

II. Objetos, empaques, envases, embalajes, papelería, material publicitario de cualquier medio o similares relacionados directa o indirectamente con los objetos referidos en la fracción anterior;

III. Anuncios, letreros, rótulos, papelería y similares que se refieran directamente a cualquiera de los objetos previstos en la fracción I del presente artículo, y que den lugar a que se infrinja alguno de los derechos tutelados por la Ley o este Reglamento;

IV. Utensilios, instrumentos, materiales, equipos, suministros e insumos utilizados en la fabricación, elaboración, obtención, depósito, circulación o distribución de cualquiera de los objetos señalados en las fracciones anteriores, y

V. Cualquier otro objeto del que se puedan inferir elementos de prueba.

La orden de suspensión o cese de los actos que presuntamente constituyan infracción en materia de comercio podrá recaer sobre la representación, recitación, ejecución pública, radiodifusión, transmisión, comunicación al público por redes de telecomunicaciones o cualquier otra forma de utilización o explotación de derechos de autor, derechos conexos, reservas de derechos, imagen de una persona, así como sobre todo acto que permita tener un dispositivo o sistema cuya finalidad sea desactivar los dispositivos electrónicos de protección de un programa de cómputo. 
El aseguramiento podrá recaer en mercancías, productos y cualesquiera otros bienes en los que se materialicen las infracciones previstas en el artículo 231 de la Ley."

Ahora bien, una vez establecido lo que antecede, resulta necesario considerar que, de conformidad con el conjunto normativo de referencia; para obtener un oficio de imposición de medidas provisionales expedido por el IMPI, es necesario cubrir los siguientes requisitos:

I. Acreditar ser el titular del derecho y cualquiera de los siguientes supuestos:

a) La existencia de una violación a su derecho;

b) Que la violación a su derecho sea inminente;

c) La existencia de la posibilidad de sufrir un daño irreparable, y

d) La existencia de temor fundado de que las pruebas se destruyan, oculten, pierdan o alteren.

II. Otorgar fianza suficiente para responder de los daños y perjuicios que se pudieran causar a la persona en contra de quien se haya solicitado la medida, y

III. Proporcionar la información necesaria para la identificación de los bienes, servicios o establecimientos con los cuales o en donde se comete la violación a los derechos de propiedad industrial.

Además de sujetarse a los siguientes lineamientos legales:

a) La persona contra la que se haya adoptado la medida podrá exhibir contrafianza para responder de los daños y perjuicios que se causen al solicitante de la misma, a efecto de obtener su levantamiento.

b) El Instituto deberá tomar en consideración la gravedad de la infracción y la naturaleza de la medida solicitada para adoptar la práctica de ésta. 
c) Para determinar el importe de la fianza el Instituto tomará en consideración los elementos que le aporte el titular del derecho así como los que se desprendan de las actuaciones en el expediente. El importe de la contrafianza comprenderá la cantidad afianzada por el solicitante de las medidas y un monto adicional de cuarenta por ciento sobre el que se hubiere exhibido para la fianza.

d) El Instituto podrá requerir al solicitante la ampliación de la fianza, cuando de la práctica de las medidas se desprenda que la otorgada inicialmente resulta insuficiente para responder de los daños y perjuicios que se pudieran causar a la persona en contra de quien se haya solicitado la medida. En el mismo sentido, el Instituto podrá ordenar el incremento de la contrafianza. ${ }^{30}$

Otra particularidad del sistema es que para estar en posibilidad de obtener una resolución favorable de suspensión de la libre circulación de mercancías de procedencia extranjera en frontera por parte de la autoridad administrativa y que la autoridad aduanera se encargue de su ejecución, de conformidad con las disposiciones legales aplicables, es necesario proporcionar la siguiente información:

a) El nombre del importador.

b) La descripción detallada de las mercancías.

c) La aduana por la que se tiene conocimiento que van a ingresar las mercancías.

d) El periodo estimado para el ingreso de las mercancías, el cual no excederá de quince días.

e) El almacén en el que deberán quedar depositadas las mercancías a disposiciones de la autoridad competente, el cual deberá estar ubicado dentro de la circunscripción territorial de la aduana que corresponda, y

\footnotetext{
${ }^{30}$ Artículo 199 BIS 1 LPI.
} 
IUS ET SCIENTIA (ISSN: 2444-8478) 2018, Vol. 4, nº 1, pp. 40-73

"Infracciones a los derechos de autor en México con relación al entorno digital". Fernando SOLER AGUILAR

Universidad Nacional Autónoma de México. fernandosoleraguilar@gmail.com

Enviado : 15/06/2018. Aceptado: 01/07/2018

DOI: http://dx.doi.org/10.12795/IETSCIENTIA.2018.i01.04

f) La designación o aceptación expresa del cargo de depositario. ${ }^{31}$

Por lo tanto, resultará indispensable que el titular de los derechos de autor lleve a cabo una labor de inteligencia e investigación a través de la cual pueda tener conocimiento de la información arriba indicada pues de lo contrario, la autoridad competente no estará en posibilidad de acordar de conformidad con lo solicitado.

\section{Infracciones en materia de Derechos de Autor}

Tal y como hemos establecido previamente, la LFDA contempla una serie de acciones que constituyen violación a los derechos de autor que son competencia del INDAUTOR, mismas que para clara referencia se indican en el siguiente listado:

I. Celebrar un contrato que tenga por objeto la transmisión de derechos en contravención a lo dispuesto por la ley;

II. La infracción por el licenciatario de la licencia obligatoria declarada conforme a la Ley;

III. Ostentarse como sociedad de gestión colectiva sin haber obtenido el registro ante el Instituto.

IV. No proporcionar al Instituto, sin causa justificada, los informes que deben rendir los administradores de la sociedad de gestión;

V. No insertar en una obra publicada las leyendas obligatorias establecidas en la Ley;

VI. Omitir o insertar con falsedad en una edición los datos visibles que deben aportar en las obras que se publiquen;

VII. Omitir o insertar con falsedad las menciones que deben suministrar en lugar visible de las obras que impriman;

\footnotetext{
${ }^{31}$ Artículo 149 de la Ley Aduanera.
} 
VIII. La omisión en un fonograma de las menciones que deben ostentar los fonogramas;

IX. Publicar una obra, estando autorizado para ello, sin mencionar en los ejemplares de ella el nombre del autor, traductor, compilador, adaptador o arreglista.

X. Publicar una obra, estando autorizado para ello, con menoscabo de la reputación del autor como tal y, en su caso, del traductor, compilador, arreglista o adaptador;

XI. Publicar antes que la Federación, los Estados o los Municipios y sin autorización las obras hechas en el servicio oficial.

XII. Emplear dolosamente en una obra un título que induzca a confusión con otra publicada con anterioridad;

XIII. Fijar, representar, publicar, efectuar alguna comunicación o utilizar en cualquier forma una obra literaria y artística, protegida conforme al capítulo III, del Título VII, de la Ley, sin mencionar la comunidad o etnia, o en su caso le región de la República Mexicana de la que es propia, y

XIV. Las demás que se deriven de la interpretación de la presente Ley y sus reglamentos. $^{32}$

\section{Sanciones}

De conformidad con el conjunto normativo aplicable, las infracciones en materia de derechos de autor serán sancionadas por el INDAUTOR, con arreglo a lo dispuesto por la Ley Federal del Procedimiento Administrativo con las siguientes multas:

De 5,000 hasta 15,000 días de salario mínimo en los casos previstos en las fracciones I, II, III, IV, XI, XIII y XIV.

De 1,000 hasta 5,000 días de salario mínimo en los demás casos.

\footnotetext{
${ }^{32}$ Artículo 229 LFDA.
} 
Se aplicará multa adicional de hasta 500 días de salario mínimo por día, a quien persista en la infracción. ${ }^{33}$

\section{Infracciones en materia de comercio}

El usuario del sistema de protección de los Derechos de Autor en México tiene a su disposición el siguiente catálogo de conductas que constituyen infracciones en materia de comercio cuando sean realizadas con fines de lucro directo o indirecto:

I. Comunicar o utilizar públicamente una obra protegida por cualquier medio, y de cualquier forma sin la autorización previa y expresa del autor, de sus legítimos herederos o del titular del derecho patrimonial de autor;

II. Utilizar la imagen de una persona sin su autorización o la de sus causahabientes.

III. Fijar, producir, reproducir, almacenar, distribuir, transportar o comercializar copias de obras, obras cinematográficas y demás obras audiovisuales, fonogramas, videogramas o libros protegidos por los derechos de autor o por los derechos conexos, sin la autorización de los respectivos titulares en los términos de esta Ley;

IV. Ofrecer en venta, almacenar, transportar o poner en circulación obras protegidas por esta Ley que hayan sido deformadas, modificadas o mutiladas sin autorización del titular del derecho de autor;

V. Importar, vender, arrendar o realizar cualquier acto que permita tener un dispositivo o sistema cuya finalidad sea desactivar los dispositivos electrónicos de protección de un programa de computación;

VI. Retransmitir, fijar, reproducir y difundir al público emisiones de organismos de radiodifusión y sin la autorización debida;

\footnotetext{
${ }^{33}$ Artículo 230 LFDA.
} 
VII. Usar, reproducir o explotar una reserva de derechos protegida o un programa de cómputo sin el consentimiento del titular;

VIII. Usar o explotar un nombre, título, denominación, características físicas o psicológicas, o características de operación de tal forma que induzcan a error o confusión con una reserva de derechos protegida;

IX. Utilizar las obras literarias y artísticas protegidas por el capítulo III, del Título VII de la presente Ley (De las Culturas Populares) en contravención a lo dispuesto por el artículo 158 de la misma, y

X. Las demás infracciones a las disposiciones de la Ley que impliquen conducta a escala comercial o industrial relacionada con obras protegidas por esta Ley.

\section{Sanciones}

Las infracciones en materia de comercio previstas en la LFDA, serán sancionadas por el IMPI, con las siguientes multas:

De 5,000 hasta 40,000 días de salario mínimo en los casos previstos en las fracciones I, III, IV, V, VII, VIII y IX.

De 1,000 hasta 5,000 días de salario mínimo en los casos previstos en las fracciones II y VI.

De 500 hasta 1,000 días de salario mínimo en los demás casos a que se refiere la fracción $\mathrm{X}$.

Se aplicará multa adicional de hasta 500 días de salario mínimo general vigente por día, a quien persista en la infracción. ${ }^{34}$

\footnotetext{
${ }^{34}$ Artículo 232 LFDA.
} 
Si el infractor fuese editor, organismo de radiodifusión, o cualquier persona física o moral que explote obras a escala comercial, la multa podrá incrementarse hasta en un $50 \% .^{35}$

\section{Reparación del daño por vía administrativa}

La reparación del daño material y/o moral así como la indemnización por daños y perjuicios por violación a los derechos que confiere la LFDA en ningún caso será inferior al cuarenta por ciento del precio de venta al público del producto original o de la prestación original de cualquier tipo de servicios que impliquen violación a alguno o algunos de los derechos tutelados por la Ley. ${ }^{36}$

\section{Procedimiento}

Una vez revisados los lineamientos establecidos por la LFDA, es posible advertir que en la práctica ha resultado eficiente el ejercicio de las acciones identificadas como infracciones en materia de comercio, mismas que son tramitadas ante el IMPI y se presentan con mayor frecuencia en virtud de que están directamente relacionadas con los derechos patrimoniales de los autores. Por lo tanto, consideramos oportuno identificar sus características principales en los siguientes puntos:

a) Se rigen por lo establecido en los Títulos Sexto y Séptimo de la Ley de la Propiedad Industrial.

b) El IMPI podrá adoptar las medidas provisionales previstas en la LPI.

c) El IMPI cuenta con amplias facultades para realizar investigaciones; ordenar y practicar visitas de inspección; así como requerir información y datos.

\footnotetext{
${ }^{35}$ Artículos 233 LFDA.

${ }^{36}$ Artículo 216 BIS LFDA.
} 
d) EL IMPI puede dictar resolución de suspensión de la libre circulación de mercancías de procedencia extranjera en frontera, en términos de la Ley Aduanera.

\section{Delitos en materia de Derechos de Autor}

El catálogo de conductas delictivas se encuentra contenido en el Código Penal Federal vigente en México, Título Vigésimo sexto, denominado: "De los Delitos en Materia de Derechos de Autor" y se trata de las siguientes:

a) Se impondrá prisión de seis meses a seis años y de trescientos a tres mil días multa:

I. Al que especule en cualquier forma con los libros de texto gratuitos que distribuye la Secretaría de Educación Pública;

II. Al editor, productor o grabador que a sabiendas produzca más números de ejemplares de una obra protegida por la Ley Federal del Derecho de Autor, que los autorizados por el titular de los derechos;

III. A quien use en forma dolosa, con fin de lucro y sin la autorización correspondiente obras protegidas por la Ley Federal del Derecho de Autor. ${ }^{37}$

b) Se impondrá prisión de tres a diez años y de dos mil a veinte mil días multa:

I. A quien produzca, reproduzca, introduzca al país, almacene, transporte, distribuya, venda o arriende copias de obras, fonogramas, videogramas o libros, protegidos por la Ley Federal del Derecho de Autor, en forma dolosa, con fin de especulación comercial y sin la autorización que en los términos de la citada Ley deba otorgar el titular de los derechos de autor o de los derechos conexos.

\footnotetext{
${ }^{37}$ Artículo $424 \mathrm{CPF}$.
} 
Igual pena se impondrá a quienes, a sabiendas, aporten o provean de cualquier forma, materias primas o insumos destinados a la producción o reproducción de obras, fonogramas, videogramas o libros a que se refiere el párrafo anterior, o

II. A quien fabrique con fin de lucro un dispositivo o sistema cuya finalidad sea desactivar los dispositivos electrónicos de protección de un programa de computación. $^{38}$

c) Se impondrá prisión de seis meses a seis años y de cinco mil a treinta mil días multa, a quien venda a cualquier consumidor final en vías o en lugares públicos, en forma dolosa, con fines de especulación comercial, copias de obras, fonogramas, videogramas o libros, a que se refiere la fracción I del artículo anterior.

Si la venta se realiza en establecimientos comerciales, o de manera organizada o permanente, se estará a lo dispuesto en el artículo 424 Bis de este Código. ${ }^{39}$

d) Se impondrá prisión de seis meses a dos años o de trescientos a tres mil días multa, al que a sabiendas y sin derecho explote con fines de lucro una interpretación o una ejecución. ${ }^{40}$

e) Se impondrá prisión de seis meses a cuatro años y de trescientos a tres mil días multa, en los casos siguientes:

I. A quien fabrique, importe, venda o arriende un dispositivo o sistema para descifrar una señal de satélite cifrada, portadora de programas, sin autorización del distribuidor legítimo de dicha señal, y

II. A quien realice con fines de lucro cualquier acto con la finalidad de descifrar una señal de satélite cifrada, portadora de programas, sin autorización del distribuidor legítimo de dicha señal. ${ }^{41}$

\footnotetext{
${ }^{38}$ Artículo 424 Bis CPF.

${ }^{39}$ Artículo 424 Ter CPF.

${ }^{40}$ Artículo 425 CPF.
} 
f) Se impondrá prisión de seis meses a seis años y de trescientos a tres mil días multa, a quien publique a sabiendas una obra substituyendo el nombre del autor por otro nombre. ${ }^{42}$

\section{Reparación del daño penal}

De forma equivalente a la regla establecida en materia administrativa, las sanciones pecuniarias previstas en el CPF se aplicarán sin perjuicio de la reparación del daño, cuyo monto no podrá ser menor al cuarenta por ciento del precio de venta al público de cada producto o de la prestación de servicios que impliquen violación a alguno o algunos de los derechos tutelados por la Ley Federal del Derecho de Autor. ${ }^{43}$

Los delitos previstos en este Título se perseguirán de oficio, excepto lo previsto en los artículos 424 , fracción II y $427 .{ }^{44}$

Tal y como fue expuesto previamente, la autoridad competente para conocer de estos delitos es la Unidad Especializada en Investigación de Delitos contra los Derechos de Autor y la Propiedad Industrial (UEIDDAPI).

\section{Tesis jurisprudencial relevante}

Una vez expuesto el entramado legal que nos ocupa, el lector podrá advertir que el sistema de protección de los Derechos de Autor en México, se encuentra desarrollado y cuenta con bases legales suficientes que teóricamente permiten inhibir las acciones que podrían

\footnotetext{
${ }^{41}$ Artículo $426 \mathrm{CPF}$.

${ }^{42}$ Artículo 427 CPF.

${ }^{43}$ Artículo $428 \mathrm{CPF}$.

${ }^{44}$ Artículo 429 CPF.
} 
considerarse violatorias de los derechos de autor, particularmente, a nivel nacional se cuenta con antecedentes positivos en el sentido de que la autoridad administrativa ha logrado detener la comisión de actos infractores a través de la imposición de medidas provisionales como primer paso, y de forma subsecuente con la emisión de las sanciones correspondientes, mismas que se ven reflejadas a través de multas y la definitividad de las medidas provisionales impuestas.

No omitimos mencionar que no obstante existe la vía penal, al tratarse de controversias meramente económicas, los mismos titulares de los derechos de autor y sus apoderados legales han optado por la vía administrativa a través de los mecanismos que establece la LPI y ante el IMPI, principalmente, en virtud de que ha obtenido resultados positivos con la imposición de medidas provisionales y la suspensión de la libre circulación de mercancías de procedencia extranjera en frontera.

Sin embargo, es un hecho que con el paso de los años, los avances de la tecnología y principalmente, el uso cada vez más frecuente de Internet, se ha presentado un nuevo reto para las autoridades competentes, quienes han tenido que migrar este tipo de controversias del mundo analógico al mundo digital. Lo anterior, llevó una controversia al más alto tribunal en los Estados Unidos Mexicanos, la Suprema Corte de Justicia de la Nación, quien se pronunció en los términos que se transcriben a continuación:

Época: Décima Época

Registro: 2014656

Instancia: Segunda Sala

Tipo de Tesis: Aislada

Fuente: Gaceta del Semanario Judicial de la Federación

Libro 43, Junio de 2017, Tomo II

Materia(s): Constitucional 
Tesis: 2a. CIX/2017 (10a.)

Página: 1437

\section{LIBERTAD DE EXPRESIÓN EJERCIDA A TRAVÉS DE LA RED ELECTRÓNICA (INTERNET). LA PROTECCIÓN DE LOS DERECHOS DE AUTOR NO JUSTIFICA, EN SÍ Y POR SÍ MISMA, EL BLOQUEO DE UNA PÁGINA WEB.}

Si bien los derechos de autor se reconocen como derechos humanos por el parámetro de regularidad constitucional, lo cierto es que las restricciones impuestas al derecho humano a la libertad de expresión ejercido a través de la red electrónica (Internet), con el propósito de proteger la propiedad intelectual deben referirse a un contenido concreto y no ser excesivamente amplias a efecto de cumplir con los requisitos de necesidad y proporcionalidad. De ahí que, salvo situaciones verdaderamente excepcionales, las prohibiciones genéricas al funcionamiento de páginas web por violar derechos de autor no se consideran como constitucionalmente válidas, en tanto implican una medida innecesaria o desproporcionada, al no centrarse en objetivos suficientemente precisos y al privar de acceso a numerosos contenidos, aparte de los catalogados como ilegales. Al respecto, las situaciones de excepcionalidad a la prohibición de restricciones genéricas al derecho de expresión, podrían generarse en los casos en donde la totalidad de los contenidos de una página web violen el derecho a la propiedad intelectual, lo que podría conducir al bloqueo de ésta, al limitarse únicamente a albergar expresiones que vulneren los derechos de autor.

Amparo en revisión 1/2017. Alestra, S. de R.L. de C.V. 19 de abril de 2017. Unanimidad de cuatro votos de los Ministros Alberto Pérez Dayán, Javier Laynez Potisek, José Fernando Franco González Salas y Eduardo Medina Mora I. Impedida: 
Esta tesis se publicó el viernes 30 de junio de 2017 a las 10:36 horas en el Semanario Judicial de la Federación.

No obstante que de la lectura puntual de dicho criterio se desprende con claridad que en realidad el problema fue que se bloqueó todo el contenido de la página web y no sólo el que era presuntamente infractor, la directriz que se comenta ha generado en la autoridad administrativa cierta renuencia a acordar de conformidad la imposición de medidas provisionales a sitios de Internet, lo cual ha constituido un retroceso en el avance que se tenía en esta dirección.

Sin embargo, consideramos que dependerá justamente de los autores, sus causahabientes y sus apoderados, que la autoridad acuerde de conformidad una solicitud de imposición de medidas provisionales a un sitio web nuevamente, tomando en cuenta los fundamentos legales correspondientes, cumpliendo con los requerimientos respectivos y sobre todo, siendo muy específicos en el contenido que corresponda, aspecto que con el apoyo técnico suficiente hará posible obtener una solución favorable a los intereses de los titulares de los derechos reconocidos por el sistema de protección de los derechos de autor en México.

\section{Conclusiones}

A manera de conclusiones, proponemos al lector una serie de principios generales que rigen el sistema de protección de los derechos de autor en la República Mexicana, que le permitirán tener una aproximación general al tema y a su vez, orientar su actuar ante el conocimiento de una actividad infractora en su perjuicio.

- Opera la prohibición general de no uso de la obra por quien no sea su autor. 
- Los Derechos de Autor son oponibles a todos, aunque existen excepciones y limitaciones contempladas por la LFDA.

- Infracción es toda utilización no autorizada de una obra protegida por derechos de autor cuando dicha autorización es requerida por la Ley.

- La clasificación de las infracciones autorales es la siguiente: Infracciones en materia de derechos de autor; Infracciones en materia de comercio y Delitos en materia de derechos de autor.

- En México, existen múltiples legislaciones aplicables.

- En México, contamos con múltiples mecanismos de protección.

- En consecuencia, múltiples autoridades competentes.

- Se cuenta con un amplio y específico catálogo de infracciones.

- Las sanciones económicas son por montos considerables.

- Es posible reclamar la reparación del daño.

- Existe la posibilidad de solicitar medidas precautorias.

- Podemos solicitar visitas de inspección por parte de las autoridades competentes.

- Las autoridades competentes pueden girar requerimientos de informes y datos.

- Se puede solicitar la suspensión de la libre circulación de mercancías de procedencia extranjera.

- La experiencia en México ha demostrado que el mecanismo más efectivo, eficiente y rápido para combatir infracciones a los derechos de autor, es el denominado: Infracción en Materia de Comercio, mismo que se tramita ante el IMPI.

\section{Bibliografía}

DE LA PARRA, E., Derechos Humanos y Derechos de Autor, Universidad Nacional Autónoma de México e Instituto de Investigaciones Jurídicas, México, 2010. 
IUS ET SCIENTIA (ISSN: 2444-8478) 2018, Vol. 4, nº 1, pp. 40-73

"Infracciones a los derechos de autor en México con relación al entorno digital". Fernando SOLER AGUILAR

Universidad Nacional Autónoma de México. fernandosoleraguilar@gmail.com

Enviado : 15/06/2018. Aceptado: 01/07/2018

DOI: http://dx.doi.org/10.12795/IETSCIENTIA.2018.i01.04

LIPSZYC, D., Derecho de Autor y Derechos Conexos, UNESCO/CERLALC/ZAVALIA, Argentina, 1993.

RANGEL MEDINA, D., Derecho Intelectual, UNAM-McGRAW HILL, México, 1998. 